Mafra, G.A. Sinalização interpretativa como ferramenta de educação patrimonial em parques urbanos: o caso do Parque da Serra do Curral de Belo Horizonte. Revista Brasileira de Ecoturismo,

\title{
Sinalização interpretativa como ferramenta de educação patrimonial em parques urbanos: o caso do Parque da Serra do Curral de Belo Horizonte
}

\section{Gisele Assis Mafra}

\section{RESUMO}

Em 2008, a Prefeitura de Belo Horizonte, através da Fundação de Parques Municipais - FPM - iniciou a implantação do Parque da Serra do Curral. Ocupando uma área de 40 hectares ao longo da Serra do Curral o parque conta com mirantes para observação da fauna e flora e contemplação da serra e seu entorno. O projeto de sinalização interpretativa já está finalizado e em fase de implantação e pretende despertar o interesse do visitante sobre recursos ambientais e culturais preservados pelo parque. A sinalização enfocará a importância histórica e cultural, para a cidade e o Estado de Minas, da Serra do Curral e de alguns pontos na paisagem observados do topo da serra. Abordará também a biodiversidade protegida pelo parque. O objetivo do projeto é que os visitantes, além de entenderem a importância de se preservar a Serra do Curral através de um parque, possam admirar a paisagem, identificar locais familiares na massa urbana da Região Metropolitana de Belo Horizonte - RMBH - e, dessa forma, se entender como parte dessa realidade. A sinalização promoverá um contato dos visitantes com a história, cultura e recursos naturais não só do parque, mas da $\mathrm{RMBH}$, podendo, dessa forma, ser um instrumento de educação patrimonial que desperte nas pessoas o interesse e a preocupação pelo patrimônio local. O presente artigo pretende apresentar o projeto de sinalização criado para o Parque da Serra do Curral e discutir como seu conteúdo poderá ser uma ferramenta de educação patrimonial com seus visitantes.

PALAVRAS-CHAVE: Educação Patrimonial, Parque Urbano, Sinalização Interpretativa

Interpretive signaling as a tool for patrimonial education in urban parks: the case of Parque da Serra do Curral of Belo Horizonte (MG), Brazil.

\section{ABSTRACT}

In 2008, Belo Horizonte City Hall, through the Municipal Parks Foundation started the implementation of Serra do Curral Park. Occupying an area of 40 hectares along Serra do Curral, the park has several viewpoints for observing the flora and the fauna, and also for contemplating the mountains and its surroundings. The interpretive signaling project has already been made and it is currently under the process of implementation. It has the intention to get the visitors' attention to all of the natural and cultural resources preserved by the park. The signs stress how valuable Serra do Curral is, historically and culturally to the City and the State of Minas Gerais. The goal of the project is to make visitors aware of the importance to maintain Serra do Curral through the Park while offering a place where they can enjoy the view and observe known locations in the Metropolitan Area of Belo Horizonte (MABH), creating a sense of belonging. The signs connect visitors to the history, culture and natural resources of, not only the park but also of the $\mathrm{MABH}$, becoming a tool to patrimonial education and to awareness to cultural heritage. This article intends to make a presentation of the signaling project created for the Serra do Curral Park and discuss how its content can be a tool for the educational heritage of its visitors

KEYWORDS: Patrimonial Educations, Urban Parks, Interpretative Signaling. 
Sinalização interpretativa como ferramenta de educação patrimonial em parques urbanos: o caso do Parque da Serra do Curral de Belo Horizonte.

\section{Introdução}

Os parques urbanos têm o seu foco no uso público, pois são locais de visitação, lazer e contemplação dos moradores de centros urbanos. São importantes para a manutenção da qualidade de vida nas grandes cidades pois servem como controladores de temperatura e poluição, umidificam o ar e fornecem sombra. Em Belo Horizonte há 69 parques urbanos, com diferentes especificidades e formas de manejo, geridos pela Fundação de Parques Municipais - FPM.

Em 2008, a FPM iniciou a implantação do Parque da Serra do Curral. Ocupando uma área de 40 hectares ao longo da Serra do Curral, o parque conta com 10 mirantes para observação da fauna e flora e contemplação da serra e seu entorno. $O$ plano de manejo ainda está sendo elaborado, mas o projeto de sinalização interpretativa já está finalizado, faltando apenas a instalação das placas, e pretende despertar o interesse do visitante sobre recursos ambientais e históricos preservados pelo parque. A visitação ao parque só será permitida após a finalização destes planos e projetos.

Para enriquecer a experiência do visitante, nos mirantes serão implantadas placas que auxiliarão a interpretação do que é avistado daquele ponto, através de fotos panorâmicas e texto. Nessa sinalização serão enfocados elementos com importância histórica e cultural para a cidade e o estado de Minas, tais como a Lagoa da PampuIha, as cidades da Região Metropolitana de Belo Horizonte - RMBH, a Serra do RolaMoça, o Pico de Itabirito e a Avenida Afonso Pena. Também será trabalhada a questão ambiental com a abordagem da biodiversidade local. Junto ao marco de tombamento da serra realizado pelo Instituto do Patrimônio Histórico e Artístico Nacional, será, ainda, apresentada a relação da Serra do Curral e a história da cidade. O objetivo desse plano de sinalização é que os visitantes, além de entenderem a importância de se preservar a Serra do Curral através de um parque, possam admirar a paisagem, identificar locais familiares na massa urbana da RMBH e, dessa forma, se entender como parte dessa realidade, e ainda, se sensibilizar para a importância histórica e social desses elementos. É uma forma também de estimular os visitantes a, posteriormente, conhecerem mais sobre os locais avistados dos mirantes.

Pretende-se que a sinalização promova um contato dos visitantes com a história, cultura e recursos naturais não só do parque, mas da $\mathrm{RMBH}$ como um todo, podendo, dessa forma, ser um instrumento de educação patrimonial que desperte nas pessoas o interesse e a preocupação pelo patrimônio local.

O presente artigo apresenta o projeto de sinalização interpretativa criado para o Parque da Serra do Curral e discute sua possível utilização como ferramenta de educação patrimonial com seus visitantes.

Para desenvolver este estudo de caso foi realizada pesquisa bibliográfica sobre técnicas e metodologias de sinalização interpretativa e de educação patrimonial, análise de trabalhos no Brasil e no exterior que utilizam a sinalização como metodologia de educação ambiental e patrimonial, análise de mapas temáticos e fotografias, e observações sobre os atrativos e infraestrutura da Serra do Curral. 


\section{Patrimônio e educação}

Patrimônio é uma palavra latina (patrimonium) e significa herança do pai. O conceito de patrimônio se consolidou com a contribuição de discussões e trabalhos ao longo de vários séculos. A ideia de conservação e valorização de bens históricos iniciou-se na França na época da Revolução Francesa, quando a necessidade de romper com a ordem política e social pré-Revolução incitou os revolucionários a destruírem construções e monumentos associados à nobreza, valorizando o que entendiam como res publica, (coisa pública, em latim). Esses atos de vandalismo, consequentemente, motivaram reações no sentido de garantir a conservação dessas construções, dando início a uma fase de reconhecimento e classificação dos bens públicos que pudessem transmitir o sentimento de nacionalidade, de identidade, de pertencimento àquela nação.

No Brasil, a Constituição Federal de 1988, a exemplo de algumas anteriores, institui a definição oficial de patrimônio e inclui, sobretudo, aspectos que valorizavam o exercício da cidadania e abrangem os diferentes grupos sociais e culturais. No âmbito das políticas públicas, o patrimônio pretende representar a identidade brasileira e a história nacional:

Art. 216. Constituem patrimônio cultural brasileiro os bens de natureza material e imaterial, tomados individualmente ou em conjunto, portadores de referência à identidade, à ação, à memória dos diferentes grupos formadores da sociedade brasileira, nos quais se incluem:

I - as formas de expressão;

II - os modos de criar, fazer e viver;

III - as criações científicas, artísticas e tecnológicas;

IV - as obras, objetos, documentos, edificações e demais espaços destinados às manifestações artístico-culturais;

$\mathrm{V}$ - os conjuntos urbanos e sítios de valor histórico, paisagístico, artístico, arqueológico, paleontológico, ecológico e científico (BRASIL, 1988).

A identidade é a relação sentimental do indivíduo com o local onde vive (MARTINS, 2006). De acordo com Silva (2000), a identidade confere a um povo o sentimento de coletividade e pertencimento ao grupo e o diferencia dos demais. É formada através de um processo de legitimação social e cultural de objetos e costumes, símbolos que transmitem a cultura através das gerações e possibilitam a manutenção de um vínculo com o passado.

Para fortalecer e preservar o patrimônio cultural e a identidade de um povo, são utilizadas estratégias como tombamento, restaurações arquitetônicas, inventariamento dos bens, implantação de museus e centros de cultura, educação patrimonial, utilização como atrativos turísticos, etc. Essas ações são complementares e, na maioria das vezes, desenvolvidas em conjunto. Dentre elas, a educação patrimonial surge com o objetivo de sensibilizar a população sobre o contexto histórico e cultural no qual está inserida, de forma a visualizar os elementos representativos deste contexto e sua 
Sinalização interpretativa como ferramenta de educação patrimonial em parques urbanos: o caso do Parque da Serra do Curral de Belo Horizonte.

importância no fortalecimento da identidade de um povo. Educação patrimonial é um "processo permanente e sistemático de trabalho educacional centrado no patrimônio cultural como fonte primária de conhecimento e enriquecimento individual e coletivo" (HORTA; GRUNBERG; MONTEIRO, 1999, p. 6)

A partir do conhecimento sobre sua herança cultural e do entendimento de como ela está presente no seu cotidiano, as pessoas se motivam a vivenciar, se apropriar e contribuir com a preservação do seu patrimônio histórico-cultural, além de estimular o desenvolvimento de novas expressões culturais na comunidade. Esta é a função da educação patrimonial, aproximar o indivíduo de sua cultura. De acordo com Horta "O conhecimento crítico e a apropriação consciente por parte das comunidades $e$ indiví-duos do seu 'patrimônio' são fatores indispensáveis no processo de preservação sustentável desses bens, assim como no fortalecimento dos sentimentos de identidade e cidadania" (idem, 1999, p.6).

Uma das ferramentas para aproximar a comunidade de seu patrimônio é a interpretação da paisagem que desperta o interesse e a atenção de moradores e turistas por determinado bem ou região. A interpretação é "uma atividade educacional que objetiva revelar significados e relações através da utilização de objetos originais, de experiências de primeira mão e por meio de mídia ilustrativa, ao invés de simplesmente comunicar informações factuais” (TILDEN, 1967, apud MURTA, 2005, p. 14)

A interpretação como estratégia de educação instiga o visitante a fazer outras descobertas, a ampliar seu olhar e encontrar singularidades e significados marcantes do lugar, como destaca Murta (2005, p. 14): "Mais que informar, interpretar é revelar significados, é provocar emoções, é estimular a curiosidade, é entreter e inspirar novas atitudes no visitante, é proporcionar uma experiência inesquecível com qualidade". A interpretação trabalha com os sentidos e a sensibilidade do turista, que deixa de ser um mero expectador e passa a entender o local e, consequentemente, a se preocupar com sua preservação. Desta forma, a visitação turística passa a ser menos ameaçadora à preservação do patrimônio. "Através da interpretação, a compreensão; através da compreensão, a apreciação, a proteção" (TILDEN, 1967, apud MURTA, 2005, p. 15).

A interpretação pode ser realizada através de visitas guiadas, sinalização, som e imagem, panfletos e guias impressos, apresentações artísticas. A escolha da estratégia interpretativa depende das características do local a ser interpretado, do público que se deseja atingir e do objetivo da atividade.

A sinalização, através de placas e painéis, é a forma mais comum de interpretação. Em geral, apresenta textos complementados por ilustrações como desenhos, mapas e fotografias que facilitam o entendimento e deixam a experiência mais agradável. A função dessa sinalização é atrair o visitante para detalhes, aprimorar seu oIhar e instigá-lo a descobrir mais informações. Normalmente implantadas ao longo de um roteiro de visitação, as placas servem para reforçar o tema central do percurso, além de auxiliarem o usuário a se localizar e orientar. Em alguns momentos, são tam- 
bém utilizadas para informar sobre regulamentos e formas de funcionamento dos locais visitados.

\section{Contextualização do Parque da Serra do Curral e Sinalização Interpretativa}

Os 69 parques municipais de Belo Horizonte se localizam em área urbana, constituindo-se como opções de lazer de grande parte da população da cidade e de seu entorno. Dessa forma, além de áreas de conservação ambiental, são espaços de uso da população para prática de esportes, descanso, lazer, realização de atividades culturais e eventos, contemplação da natureza, etc. Essas multifunções, nem sempre harmoniosas, dos parques urbanos têm provocado o desenvolvimento de um modelo de gestão específico para esses espaços.

A FPM, desde 2008, tem trabalhado na implantação do Parque da Serra do Curral, com o objetivo de preservar o patrimônio ambiental e cultural da Serra do Curral. Principal fonte de inspiração para o nome da região onde foi construída Belo Horizonte, Curral Del Rei, a serra serve de moldura para a cidade. Com uma extensão de 11 quilômetros e altitude de até 1.390 metros em seu ponto mais alto, as curvas de suas montanhas podem ser vistas de grande parte dos bairros da capital. Serve de limite entre os municípios de Belo Horizonte e Nova Lima. Pela sua presença marcante na paisagem e no cotidiano da cidade, foi escolhida pelos próprios moradores como símbolo de Belo Horizonte.

É composta por uma sucessão de camadas de rochas de composição variada, representada por itabiritos, dolomitos, quartizitos, filitos e xistos diversos, apresentando formação típica do conjunto que compõe o "Quadrilátero Ferrífero", o que motivou a exploração de suas jazidas, modificando e descaracterizando a paisagem. O Instituto do Patrimônio Histórico e Artístico Nacional - Iphan - realizou o tombamento da Serra do Curral em 1960, incluindo o conjunto paisagístico do pico e de sua parte mais baixa e nobre. Em 1991, o alinhamento das montanhas também foi incluído como bem tombado.

A implantação deste parque é mais uma ação para a conservação da Serra do Curral, pois contribui para a diminuição dos focos de incêndios, a recuperação da mata na base da serra e o controle dos processos erosivos, além de proporcionar mais segurança e acessibilidade nas trilhas locais.

O parque abrange uma área de 40 hectares e serve de corredor ecológico interligando outras unidades de conservação como o Parque Municipal das Mangabeiras, a Reserva Particular do Patrimônio Natural Mata do Jambreiro e a Mata da Baleia, totalizando mais de 1.500 hectares de vegetação preservada em plena metrópole.

A visitação ao parque será feita através de uma trilha linear de 3.950 metros de extensão que se inicia na Portaria 1, na Praça Estado de Israel, e se estende pelo topo da serra até a Portaria 2, no Parque das Mangabeiras, como pode ser observado na Figura 1. 
Sinalização interpretativa como ferramenta de educação patrimonial em parques urbanos: o caso do Parque da Serra do Curral de Belo Horizonte.

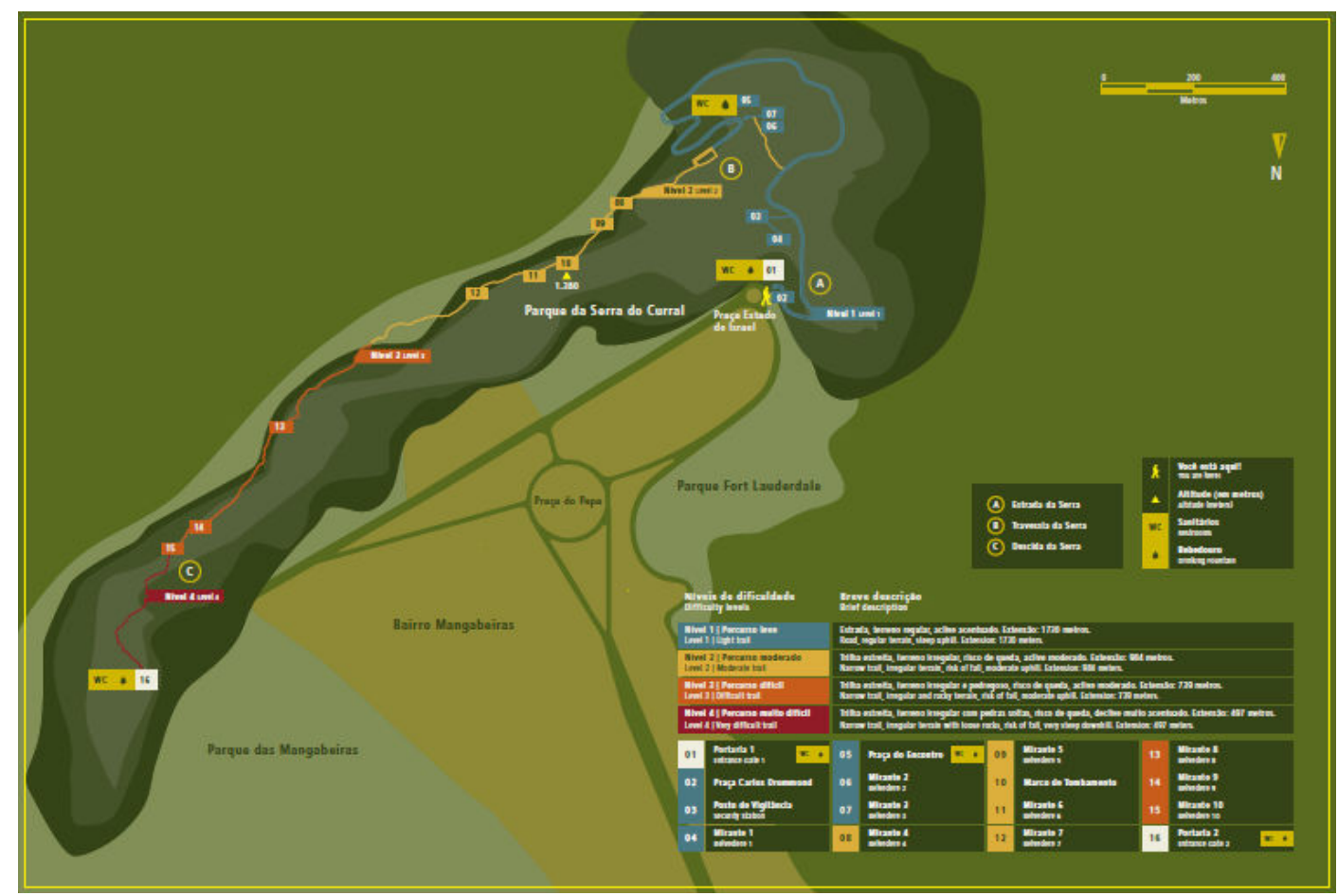

Figura 1 - Mapa do Parque da Serra do Curral, elaborado pela empresa Hardy Design, com informações fornecidas pela FPM.

No parque estão sendo instalados, além das duas portarias, guarita de vigilância, duas praças, equipamentos de ginástica, bebedouros, guarda-corpos, banheiros, trilhas e 10 mirantes. Uma das praças terá o nome de Praça Carlos Drummond de Andrade (Figura 2), em homenagem ao poeta mineiro que várias vezes se inspirou na Serra do Curral, e a outra de Praça do Encontro, sendo esta o ponto limite para acesso de veículos.

Para facilitar a orientação, o percurso pelo parque foi dividido em Subida da Terra, trecho entre Portaria 1 e Praça do Encontro, Travessia da Serra, que se inicia na Praça do Encontro e se estende por todo o topo da serra, e Descida da Serra, que finaliza na Portaria 2. Para a segurança dos usuários, o percurso foi classificado em níveis de dificuldade de acordo com o tipo de terreno, inclinação e largura da trilha. Assim, foram definidos 4 níveis de dificuldade que se sucedem gradativamente ao longo dos $4 \mathrm{~km}$.

A visitação ao Parque da Serra do Curral é fortemente marcada pela observação da paisagem. O visitante tem, a quase todo o momento, uma ampla visão tanto da região que se estende em direção ao norte quanto para o sul. Esse cenário a todo tempo atrai o olhar do visitante, normalmente acostumado a ter sua observação limitada por obstáculos como edifícios e montanhas. Assim, surgiu o interesse da administração do parque em utilizar a sinalização para estimular a observação e a interpretação da paisagem. 

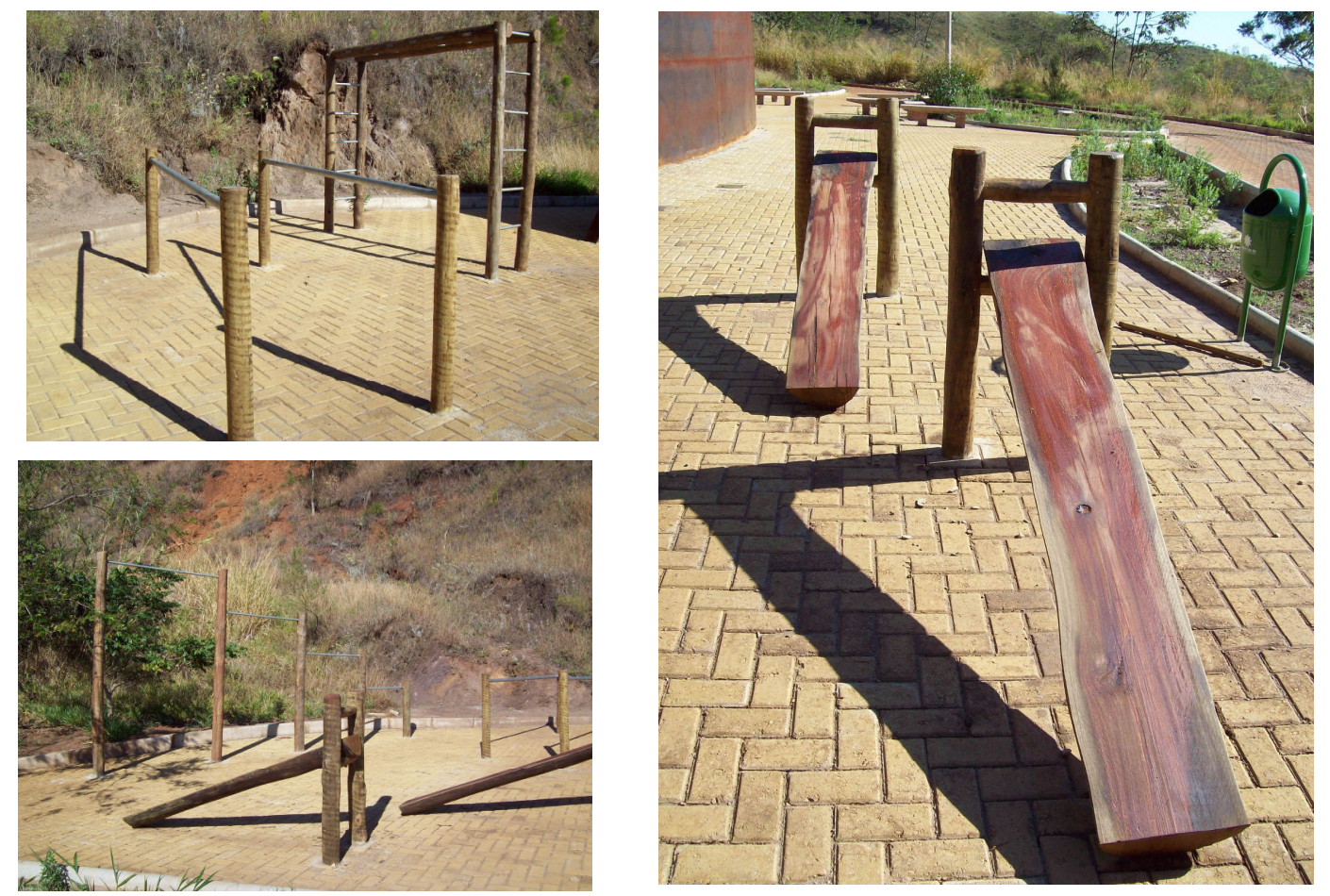

FIGURA 2 - Praça Carlos Drummond de Andrade, com equipamentos de ginástica. FOTOS - Gisele Mafra (2009)

O Mirante 1 foi escolhido para abordar a biodiversidade existente no parque, pois em seu entorno podem ser avistados vários exemplares da flora local. Além disso, por estar localizado abaixo do alinhamento da serra, a uma altitude de 1.290 metros, a paisagem avistada neste ponto não tem grande amplitude, sendo melhor observada de outros pontos da trilha. Nele, será implantada uma placa de 60 centímetros de largura e 136 centímetros de comprimento, que abordará a flora do parque (Figura 3). Conterá um quadro relacionando os exemplares mais encontrados, identificados pelo nome popular e científico, e informações sobre coloração e época de floração, complementados pelo desenho da planta. Ainda haverá o seguinte texto introdutório:

\begin{abstract}
Mirante 1
A Exuberância da Vegetação

A vegetação do Parque da Serra do Curral reúne espécies de Campos de Altitude e Cerrado. Os Campos se desenvolvem em áreas rochosas e elevadas e apresentam espécies de pequeno porte como arbustos e gramíneas. A vegetação típica do Cerrado possui troncos e ramos retorcidos, cascas espessas e folhas grossas. A canela-de-ema, um dos arbustos encontrados no parque, exibe suas belas flores no verão. Há também espécies arbóreas de maior porte como a quaresmeira, que recebe esse nome devido às suas flores roxas que florescem na época da Quaresma (FUNDAÇÃO DE PARQUES MUNICIPAIS, 2009, p. 14).
\end{abstract}


Sinalização interpretativa como ferramenta de educação patrimonial em parques urbanos: o caso do Parque da Serra do Curral de Belo Horizonte.

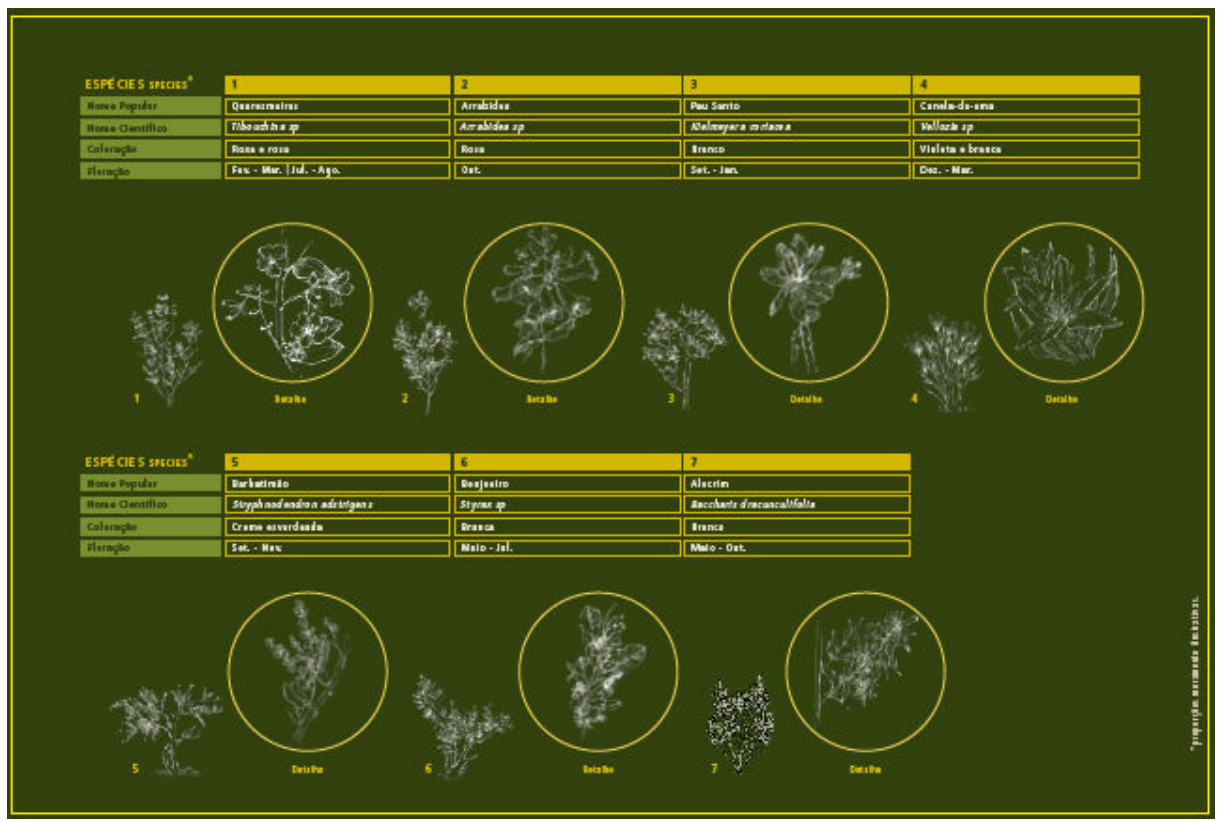

Figura 3 - Esquema gráfico da placa sobre flora, elaborado pela empresa Hardy Design, com informações fornecidas pela FPM.

O mesmo esquema será feito na placa sobre a fauna (Figura 4), que apresentará as espécies mais representativas, com o nome popular e científico, tamanho médio, desenho e o seguinte texto:

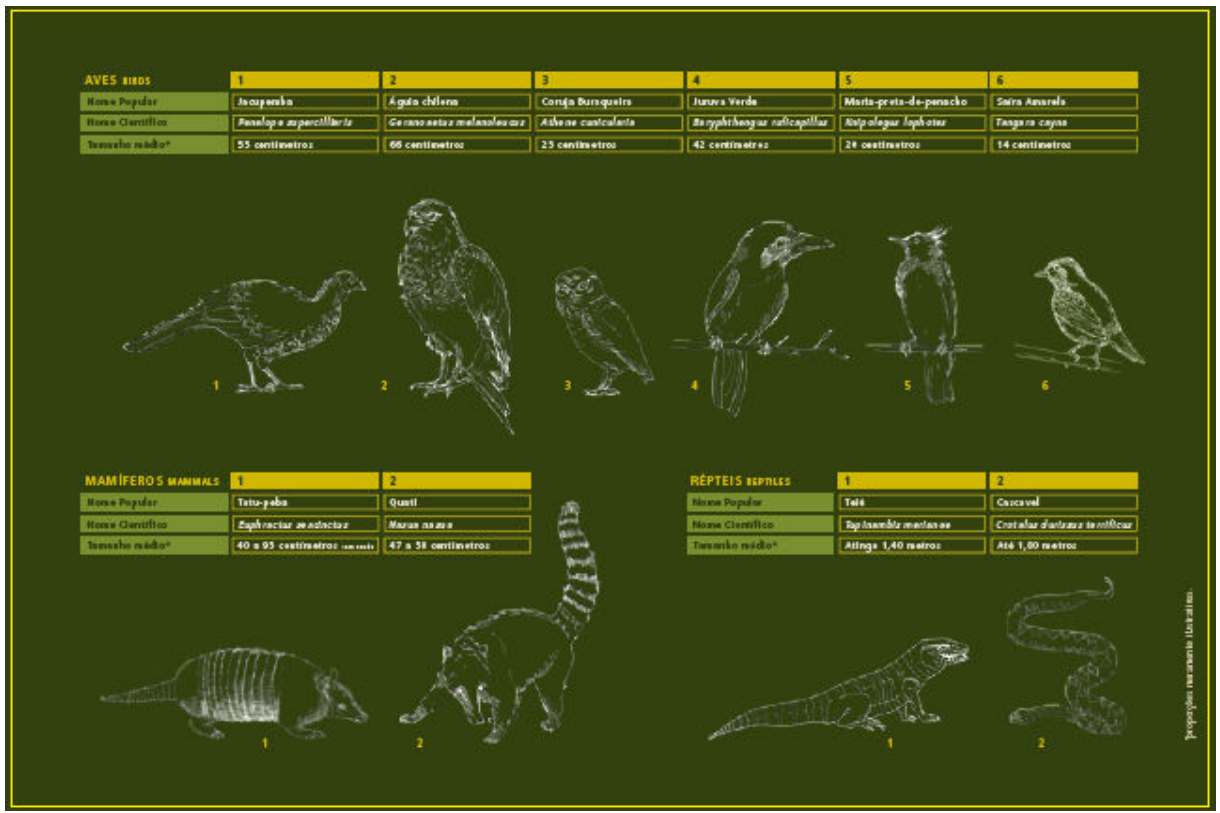

Figura 4 - Esquema gráfico da placa sobre fauna, elaborado pela empresa Hardy Design, com informações fornecidas pela FPM. 
Mirante 1

A Riqueza da Fauna

A fauna do Parque da Serra do Curral é bastante diversificada, devido ao corredor ecológico que o parque forma com a Mata do Jambreiro, a Mata da Baleia e o Parque das Mangabeiras. Juntos, abrangem mais de 1.500 hectares de vegetação preservada em plena metrópole. Dos animais do parque, as aves são as mais representativas. Foram identificadas 125 espécies, algumas endêmicas do Cerrado como a campainha-azul e outras comuns em regiões montanhosas como a águiachilena, também encontrada na Cordilheira dos Andes (FUNDAÇÃO DE PARQUES MUNICIPAIS, 2009, p. 14).

O Mirante 2 possui um dos 3 marcos de tombamento da Serra do Curral e terá apenas placas direcionais.

O Mirante 3, a uma altitude de 1.328 metros, está localizado na Praça do Encontro (Figura 5), antes do início da Trilha Travessia da Serra. Deste mirante se tem a visualização mais completa, sendo o ponto de onde é possível apreciar a paisagem em praticamente todas as direções. Uma rampa ligando a praça ao mirante garante que qualquer visitante possa acessar este ponto, inclusive idosos e pessoas com necessidades especiais que utilizarão veículos autorizados para chegar até a Praça do Encontro.

A partir deste mirante, a sinalização interpretativa abordará a paisagem. As placas, no tamanho $60 \mathrm{~cm} \times 90 \mathrm{~cm}$, terão fotos panorâmicas, em preto e branco, e texto sobre os principais elementos que podem ser observados naquele ponto. Para facilitar a interpretação da paisagem, esses elementos serão destacados na fotografia com o uso de sombreamento, como na Figura 6.

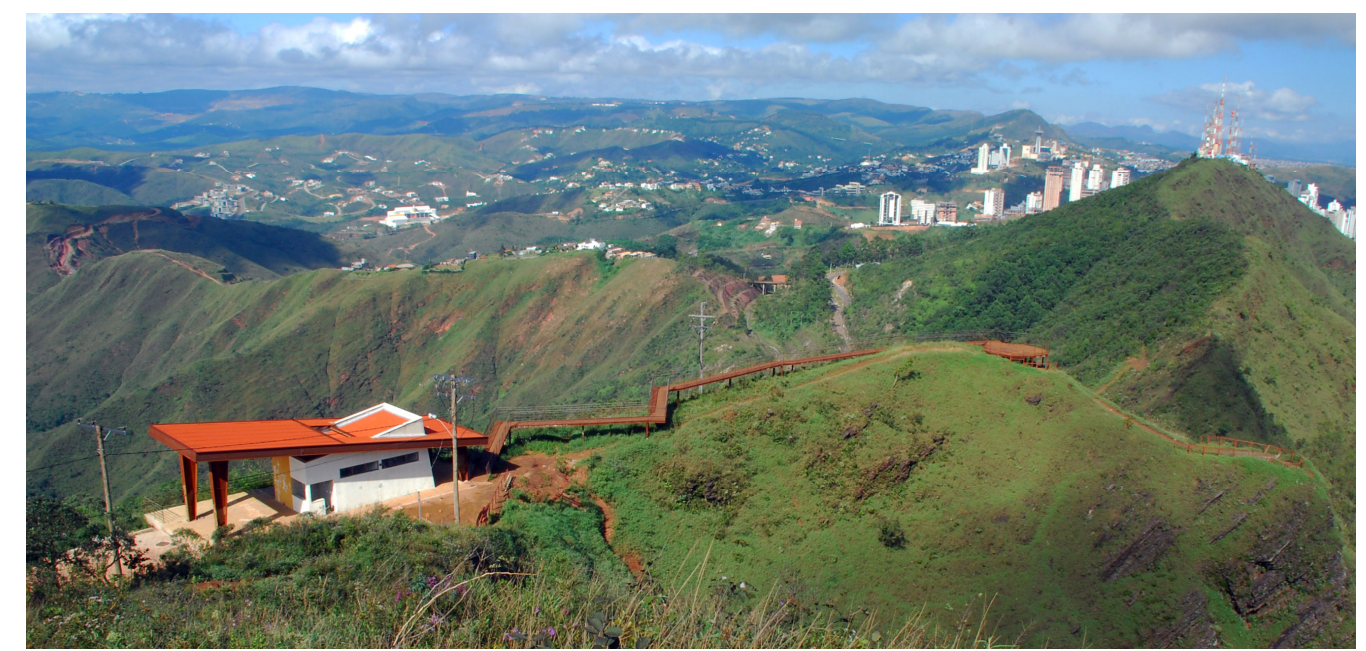

FIGURA 5 - Praça do Encontro (ainda em obras), Mirante 3 e a rampa que dá acesso a ele. FOTO - Celso Santa Rosa (2008) 
Sinalização interpretativa como ferramenta de educação patrimonial em parques urbanos: o caso do Parque da Serra do Curral de Belo Horizonte.

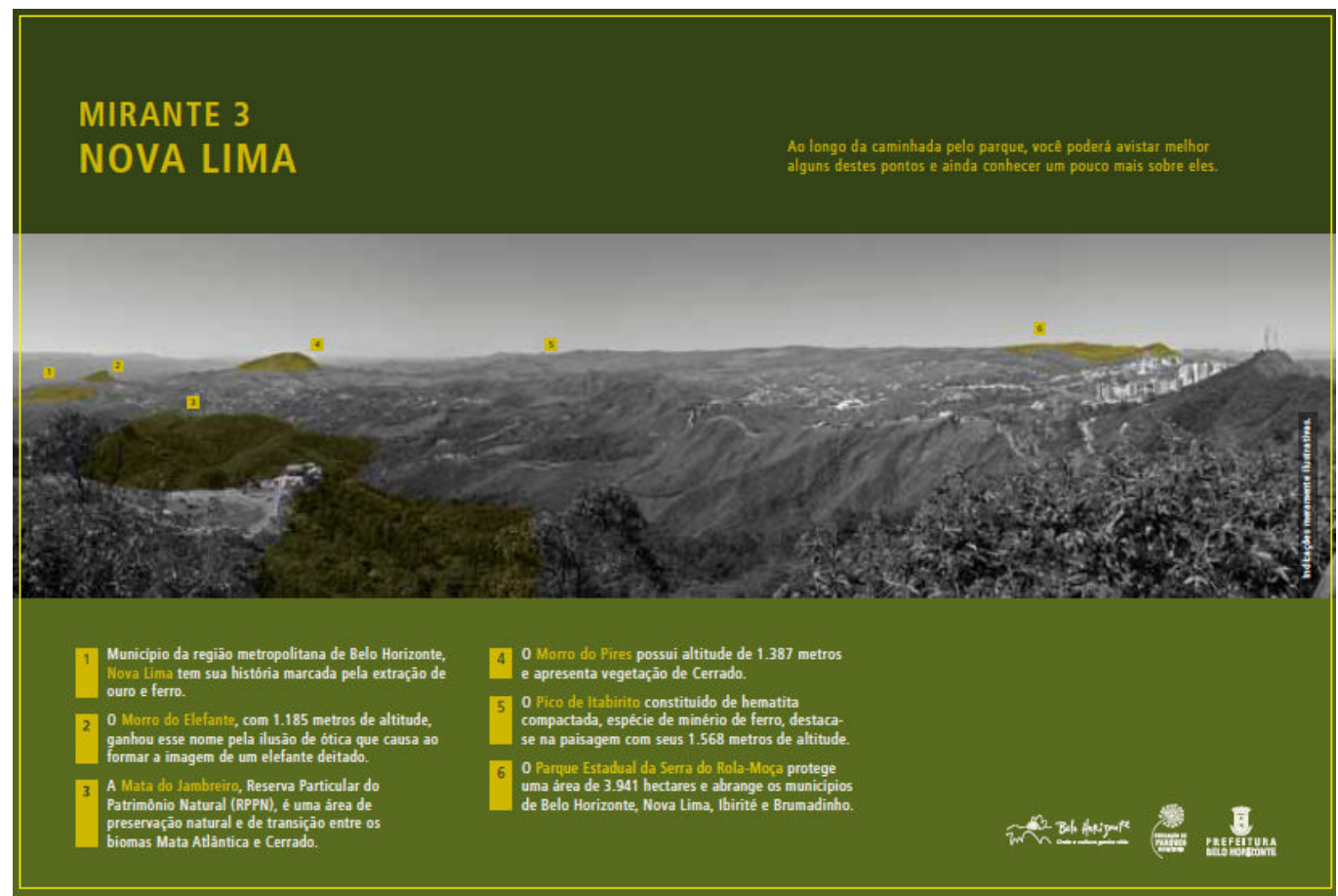

Figura 6 - Placa do Mirante 3 Nova Lima com foto panorâmica e texto. Elaborada pela empresa Hardy Design, com informações fornecidas pela FPM.

Acredita-se que alguns usuários optarão por não realizar a Travessia da Serra, por ser um trecho de maior dificuldade e, portanto, chegarão apenas até o Mirante 3. Por este motivo e também por ser um local que possibilita a visualização de uma área maior, a sinalização deste mirante abordará um número maior de elementos. Para tanto, será instalada uma placa com informações sobre a paisagem em direção ao município de Nova Lima e outra que abordará a região de Belo Horizonte. Como esta última conterá mais informações, terá o dobro do comprimento padrão (180 centímetros). ao 10:

Segue abaixo o conteúdo da sinalização que será implantada nos Mirantes 3

Mirante 3

Belo Horizonte

Contagem é um município da região metropolitana de Belo Horizonte, com economia baseada na atividade industrial.

$\mathrm{Na}$ jazida do Acaba Mundo é feita extração de dolomita, minério utilizado na fabricação de refratários, no agronegócio e na construção civil.

Fundado em 1990, o Parque Juscelino Kubitschek oferece equipamentos para prática de esportes e abriga vários eventos, sendo uma importante opção de lazer para a comunidade.

Conjunto Governador Juscelino Kubitschek, mais conhecido por Edifício JK, é um complexo constituído por dois blocos, que totalizam quase 1100 apartamentos e abrigam cerca de cinco mil moradores.

A Lagoa da Pampulha, construída na década de 1940, possui vários 
projetos de Oscar Niemeyer no seu entorno, além do Estádio Mineirão. Inaugurado em 1897, o Parque Municipal Américo Renné Giannetti contribui para amenizar o clima da região central da cidade.

O Museu de História Natural e Jardim Botânico da UFMG é uma vitrine viva da biodiversidade do Brasil: $600 \mathrm{mil} \mathrm{m}^{2}$ de área verde, com significativos exemplares de fauna e flora.

O Parque das Mangabeiras conserva em sua área de 2,4 milhões de metros quadrados imensa mata nativa rica em espécies da fauna e da flora do país e 25 nascentes da Bacia do Rio São Francisco.

O Palácio das Mangabeiras é a residência oficial do governador mineiro. Foi projetado a pedido de Juscelino Kubitschek durante sua gestão como governador.

A Praça Israel Pinheiro ganhou o nome de Praça do Papa depois da missa campal realizada, em 1980, pelo Papa João Paulo II (FUNDAÇÃO DE PARQUES MUNICIPAIS, 2009, p. 17).

Mirante 3

Nova Lima

Município da região metropolitana de Belo Horizonte, Nova Lima tem sua história marcada pela extração de ouro e ferro.

O Morro do Elefante, com 1.185 metros de altitude, ganhou esse nome pela ilusão de ótica que causa ao formar a imagem de um elefante deitado.

A Mata do Jambreiro, Reserva Particular do Patrimônio Natural (RPPN), é uma área de preservação natural e de transição entre os biomas Mata Atlântica e Cerrado.

O Morro do Pires possui altitude de 1.387 metros e apresenta vegetação de Cerrado.

O Pico de Itabirito constituído de hematita compactada, espécie de minério de ferro, destaca-se na paisagem com seus 1.568 metros de altitude.

O Parque Estadual da Serra do Rola-Moça protege uma área de 3.941 hectares e abrange os municípios de Belo Horizonte, Nova Lima, Ibirité e Brumadinho (FUNDAÇÃO DE PARQUES MUNICIPAIS, 2009, p. 18).

Mirante 4

Pampulha

A Lagoa da Pampulha foi construída na década de 1940, durante a gestão do prefeito Juscelino Kubitscheck. Para compor o seu entorno, Oscar Niemeyer projetou um conjunto arquitetônico que se tornou referência mundial e influenciou toda a arquitetura moderna brasileira. Fazem parte do conjunto: a Igreja de São Francisco de Assis, o Museu de Arte da Pampulha, a Casa do Baile e o late Tênis Clube.

A orla da Pampulha concentra várias opções de lazer, como o ginásio do Mineirinho, a Fundação Zoo-Botânica e pistas para ciclismo e caminhada. É lá também que está o Estádio Governador Magalhães Pinto, mais conhecido como Mineirão. 
Sinalização interpretativa como ferramenta de educação patrimonial em parques urbanos: o caso do Parque da Serra do Curral de Belo Horizonte.

Também na década de 1940, foi construído o campus Pampulha da Universidade Federal de Minas Gerais (UFMG).

"Com a obra da Pampulha o vocabulário plástico da minha arquitetura, num jogo inesperado de retas e curvas, começou a se definir" Oscar Niemeyer (FUNDAÇÃO DE PARQUES MUNICIPAIS, 2009, p. 19).

Mirante 5

Montanhas

O Pico de Itabirito, localizado no município de Itabirito, tem um importante valor histórico, pois, na época das bandeiras, servia como referência de direção para os paulistas que se dirigiam às minas e vilas que surgiram na região.

O Parque Estadual da Serra do Rola-Moça protege uma área de 3.941 hectares e abrange os municípios de Belo Horizonte, Nova Lima, Ibirité e Brumadinho. Está situado numa zona de transição de Cerrado para Mata Atlântica, rico em campos ferruginosos e de altitude.

A Área de Proteção Ambiental (APA) de Igarapé, com 7.100 hectares, contribui para a preservação dos recursos naturais da região (FUNDAÇÃO DE PARQUES MUNICIPAIS, 2009, p. 20).

Mirante 6

Nova Lima

Nova Lima foi fundada por bandeirantes que encontraram ribeirões auríferos no início do séc. XVIII. A região passou a atrair aventureiros em busca de ouro e logo se formou um núcleo populacional. Localizada entre a Serra do Curral e a Serra da Moeda, o município faz parte do roteiro turístico da Estrada Real.

A Mata do Jambreiro foi transformada em uma Reserva Particular do Patrimônio Natural - RPPN, abrigo para diversas espécies de animais. Com extensão de 912 hectares, possui uma área de transição entre os biomas Mata Atlântica e Cerrado e guarda nascentes de córregos da Bacia do Rio das Velhas (FUNDAÇÃO DE PARQUES MUNICIPAIS, 2009, p. 21).

Mirante 7

Afonso Pena

A Avenida Afonso Pena é considerada a avenida mais importante de Belo Horizonte. Coração econômico da capital, interliga atrativos turísticos naturais e culturais. Por ela, e no seu entorno, pode-se encontrar vários pontos turísticos da cidade como o Parque Municipal Américo Renné Giannetti e o Palácio das Artes.

Inaugurado em 1897, antes mesmo da nova capital mineira, o Parque Municipal Américo Renné Giannetti é o patrimônio ambiental mais antigo de Belo Horizonte. Projetado no final do século XIX pela Comissão Construtora encarregada de planejar a nova capital de Minas Gerais.

O Morro do Elefante, com 1.185 metros de altitude, ganhou esse nome pela ilusão de ótica que causa ao formar a imagem de um elefante deitado. 
O Morro do Pires possui altitude de 1.387 metros e apresenta vegetação de Cerrado.

"Que belo horizonte!"

Papa João Paulo II, em 1980, diante da paisagem vista da Praça Israel Pinheiro, aos pés da Serra do Curral (FUNDAÇÃO DE PARQUES MUNICIPAIS, 2009, p. 22).

\section{Mirante 8}

Cultura e Biodiversidade

Mistério: ninguém sabe o que acontece na Rua Professor Otávio CoeIho Magalhães, mais conhecida por Rua do Amendoim. Quando os carros são desligados, eles sobem, ao invés de descerem, a suave ladeira. Folclore turístico, ilusão de ótica ou fenômeno físico? Na dúvida, vale a pena conferir este fenômeno.

Situado na encosta da Serra do Curral, o Aglomerado da Serra ocupa uma área de $1.470 \mathrm{mil} \mathrm{m}^{2}$. No Aglomerado convivem vários movimentos populares, manifestações culturais, programas sociais e rádio comunitária.

O Museu de História Natural e Jardim Botânico da UFMG é uma vitrine

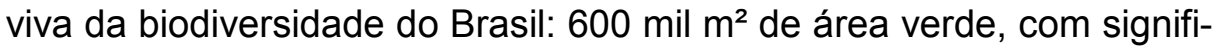
cativos exemplares da fauna e flora. Abriga, ainda, o Presépio do Pipiripau, importante tesouro da arte popular, formado por 586 figuras móveis, distribuídas por 45 cenas da vida e morte de Jesus Cristo (FUNDAÇÃO DE PARQUES MUNICIPAIS, 2009, p. 23).

Mirante 9

Ao longo da Serra

A Serra da Piedade localiza-se nos municípios de Sabará e Caeté, integrando a Reserva da Biosfera da Serra do Espinhaço. Também foi um importante referencial utilizado pelos primeiros aventureiros em busca de ouro.

O Pico Belo Horizonte, com 1.390 metros de altitude, é o ponto culminante de Belo Horizonte e da Serra do Curral.

Sabará, município da região metropolitana de Belo Horizonte, foi o primeiro povoamento de Minas Gerais. Nos séculos XVII e XVIII, Sabará foi um centro comercial estratégico diretamente ligado à Estrada Real. Possui um importante patrimônio arquitetônico, histórico e cultural e faz parte do roteiro turístico da Estrada Real.

"Mas tudo é inexoravelmente colonial:

bancos janelas fechaduras lampiões.

O casario alastra-se na cacunda dos morros,

rebanho dócil pastoreado por igrejas:

a do Carmo - que é toda de pedra,

a Matriz- que é toda de ouro."

Carlos Drummond, se referindo a Sabará, no poema Lanterna Mágica

(FUNDAÇÃO DE PARQUES MUNICIPAIS, 2009, p. 24). 
Sinalização interpretativa como ferramenta de educação patrimonial em parques urbanos: o caso do Parque da Serra do Curral de Belo Horizonte.

\section{Mirante 10}

Ao pé da Serra

O Parque das Mangabeiras foi implantado em 1982, na área onde até 1979 funcionava a Ferrobel, empresa mineradora municipal. Com projeto paisagístico de Roberto Burle Marx, o parque possui 2,4 milhões de metros quadrados de área verde preservada, além de espaços para lazer e esportes.

A Mina de Águas Claras contava com uma grande infraestrutura para extração mineral, inclusive estrada de ferro para o transporte do minério. Foi desativada em 2002 e na cava da mineração formou-se um grande lago com profundidade de até 234 metros (FUNDAÇÃO DE PARQUES MUNICIPAIS, 2009, p. 25).

Além das placas dos mirantes, haverá uma placa junto ao marco de Tombamento da Serra, localizado entre os Mirantes 5 e 6 , no alinhamento da Avenida Afonso Pena. Nesta, a foto panorâmica será substituída pela foto da Serra do Curral e o texto apresentará o patrimônio cultural e histórico representado pela serra:

\section{Marco de Tombamento da Serra}

Serra do Curral: Patrimônio Nacional Protegido

A Serra do Curral serve de moldura para a cidade de Belo Horizonte. É o limite entre os municípios de Belo Horizonte, Nova Lima, Sabará, Brumadinho e Ibirité.

Possui uma extensão de $11 \mathrm{~km}$ e altitude de até 1.390 metros no Pico Belo Horizonte, seu ponto mais alto.

Principal símbolo da capital, as curvas de suas montanhas podem ser vistas de grande parte dos bairros de Belo Horizonte e se tornaram um dos motivos de orgulho dos seus moradores.

É composta por uma sucessão de camadas de rochas de composição variada, representanda por itabiritos, dolomitos, quartizitos, filitos e xistos diversos, apresentando formação típica do conjunto que compõe o "Quadrilátero Ferrífero", o que motivou a exploração de suas jazidas, modificando a paisagem.

O Instituto do Patrimônio Histórico e Artístico Nacional tombou a Serra do Curral em 1960, incluindo o conjunto paisagístico do pico e de sua parte mais baixa e nobre. Em 1991, o alinhamento das montanhas também foi incluído como bem tombado.

"Era ao cair de uma tarde de janeiro de 1894. Depois de viajar algumas léguas do sertão mineiro (...) cheguei a estas planícies esplêndidas (...). A imensa arena brava abria-se para o oriente, encostada ao sul, à lombada do Curral e ao norte à da Contagem. $O$ sol deixara no céu o cruor do seu holocausto. Um dobre de sino embalava a tarde. Uma doce melancolia enfeitiçava o ar."

Olavo Bilac em artigo no Jornal Minas Gerais, de 25 de agosto de 1916 (FUNDAÇÃO DE PARQUES MUNICIPAIS, 2009, p. 13). 


\section{Considerações Finais}

A Serra do Curral é um forte símbolo de Belo Horizonte. Observar a biodiversidade que abriga, percorrer suas trilhas, avistar o que há depois de seu paredão, tocar as rochas da qual é constituída é a maneira ideal de realmente conhecer esse marco da capital mineira e entender a necessidade de sua preservação. Ordenar a visitação nesta área, garantindo segurança e infraestrutura, é fundamental para se conciliar preservação e uso público. O projeto de sinalização interpretativa visa despertar nos usuários essa consciência sobre a importância ambiental e cultural da serra.

Mas como a Serra do Curral é um elemento intimamente integrado ao município de Belo Horizonte e à sua região metropolitana, não se podia abordá-la isoladamente. Era preciso apresentar toda sua paisagem, invertendo a direção do olhar, que normalmente é da cidade para a serra, e estimulá-lo a partir da serra em direção à cidade. Assim, o belo-horizontino e os turistas terão a oportunidade de apreciar não só o principal símbolo de Belo Horizonte, mas também toda a cidade e seu entorno.

A observação de pontos turísticos da cidade, como a Lagoa da Pampulha, o Edifício JK, o Parque Municipal Américo Renné Giannetti, como elementos agredados à malha urbana da cidade, e não como pontos isolados, consolida a imagem da cidade, com toda sua complexidade, conflitos, belezas e patrimônios. Essa imagem, esse conceito é que se pretende construir com a educação patrimonial trabalhada através da sinalização interpretativa, e que poderá ainda ser complementada com o trabalho de condutores. A Fundação de Parques Municiapis pretende que os visitantes do Parque da Serra do Curral, sejam moradores de Belo Horizonte ou de outras localidades, saiam mais conscientes das riquezas da cidade e estimulados a conhecer ainda mais sobre os locais avistados dos mirantes. Assim, serão gerados benefícios como a ampliação do fluxo de visitantes nos demais pontos turísticos da capital, disseminação de aspectos culturais do município, população melhor instruída sobre os bens culturais existentes e, consequentemente, consciente da necessidade de preservação. É notório que quando a comunidade conhece sua cultura e com ela se identifica, se empenha na sua preservação e no seu fortalecimento. Além disso, o contato e, consequentemente, o conhecimento sobre a história e o patrimônio, por parte do turista, levam ao entendimento da importância da preservação para a valorização da cultura e para a auto-estima da comunidade local.

Como o Parque da Serra do Curral ainda não foi aberto à visitação (a inauguração estava prevista para o primeiro semestre de 2010), não foi possível testar a eficiência deste projeto. Mas com base nos estudos existentes sobre o tema e na avaliação do estudo de caso apresentado, acredita-se que seja possível utilizar a sinalização interpretativa como uma ferramenta de educação patrimonial, mesmo em uma área natural, afinal, muitas vezes bens históricos, arquitetônicos e culturais estão inseridos em ambientes naturais e vice-versa. 


\section{Referências Bibliográficas}

BRASIL. Constituição Federal. 1988. Ato das Disposições Constitucionais Transitórias, decretado e promulgado pela Assembleia Constituinte. Disponível em: $<$ http://www2.camara.gov.br/legislacao/constituicaofederal.html>. Acesso em: 10 ago. 2009.

FUNDAÇÃO DE PARQUES MUNICIPAIS. Projeto de Sinalização do Parque da Serra do Curral. Belo Horizonte: FPM, 2009.

HORTA, M.L.P.; GRUNBERG, E.; MONTEIRO, A.Q. Guia básico de Educação Patrimonial. Brasília: Instituto do Patrimônio Histórico e Artístico Nacional, Museu Imperial, 1999.

MARTINS, C. (Org.). Patrimônio Cultural: da memória ao sentido do lugar. São Paulo: Roca, 2006.

MURTA, S.M.; ALBANO, C. (Org.). Interpretar o patrimônio: um exercício do olhar. 5. ed. Belo Horizonte: UFMG, 2002.

SILVA, E.P. Património e identidade. Os desafios do turismo cultural. Porto: Universidade Fernando Pessoa, 2000. Disponível em <http://ceaa.ufp.pt/ceaa.htm>. Acesso em: 15 ago. 2004.

Gisele Assis Mafra: Fundação de Parques Municipais de Belo Horizonte.

Email:giselemafra@pbh.gov.br

Link para o currículo Lattes: http://lattes.cnpq.br/4837835978310554

Data de submissão: 30 de outubro de 2009.

Data do aceite: 02 de fevereiro de 2010. 